\title{
PTEN in Autism and Neurodevelopmental Disorders
}

\author{
Sebastian Rademacher and Britta J. Eickholt \\ Institute of Biochemistry, Charité - Universitätsmedizin Berlin, 10117 Berlin, Germany \\ Correspondence: sebastian.rademacher@charite.de
}

Phosphatase and tensin homolog (PTEN) is a classical tumor suppressor that antagonizes phosphatidylinositol 3-phosphate kinase (PI3K)/AKT signaling. Although there is a strong association of PTEN germline mutations with cancer syndromes, they have also been described in a subset of patients with autism spectrum disorders with macrocephaly characterized by impairments in social interactions and communication, repetitive behavior and, occasionally, epilepsy. To investigate PTEN's role during neurodevelopment and its implication for autism, several conditional Pten knockout mouse models have been generated. These models are valuable tools to understand PTEN's spatiotemporal roles during neurodevelopment. In this review, we will highlight the anatomical and phenotypic results from animal studies and link them to cellular and molecular findings.

\begin{abstract}
$A^{\text {utism spectrum disorders (ASDs) comprise }}$ Aa heterologous group of syndromes characterized by neuroanatomical network changes, impairment in social interactions, and verbal and nonverbal communication as well as restrictive and repetitive behavior or interests manifesting by $2-4$ years of life. In about $10 \%$ of the cases, early brain overgrowth (macrocephaly) and intellectual impairment are observed in ASD patients (Courchesne et al. 2003, 2007; Kennedy and Courchesne 2008; Donovan and Basson 2017). Classically, ASDs include autism, Asperger syndrome, childhood disintegrative disorder, and pervasive developmental disorder-not otherwise specified (PDD-NOS). The definition can also include other monogenetic neurodevelopmental diseases with autistic behavior such as Rett syndrome or Fragile-Xsyndrome. Most ASD cases occur by unknown
\end{abstract}

etiology, but there are several risk genes increasing the likelihood to develop ASD (Ramaswami and Geschwind 2018).

Though heterozygous germline mutations in the gene encoding phosphatase and tensin homolog (PTEN) are mostly linked to cancer syndromes, including Cowden, Bannayan-RileyRuvalcaba, and Proteus syndromes-commonly termed PTEN hamartoma tumor syndromes (PHTS) - they have also been described in patients with ASD (Fig. 1A; Zori et al. 1998; Goffin et al. 2001; Butler et al. 2005; Spinelli et al. 2015; Leslie and Longy 2016). PTEN, in its classical function as tumor suppressor, is the main antagonist of the phosphatidylinositol 3-phosphate kinase (PI3K)/protein kinase B (PKB/AKT) pathway by hydrolyzing phosphatidylinositol 3,4,5triphosphate $\left(\mathrm{PIP}_{3}\right)$ to phosphatidylinositol4,5-bisphosphate $\left(\mathrm{PIP}_{2}\right)$ to regulate cellular pro-

Editors: Charis Eng, Joanne Ngeow, and Vuk Stambolic

Additional Perspectives on The PTEN Family available at www.perspectivesinmedicine.org

Copyright (C) 2019 Cold Spring Harbor Laboratory Press; all rights reserved; doi: 10.1101/cshperspect.a036780

Cite this article as Cold Spring Harb Perspect Med 2019;9:a036780 
A

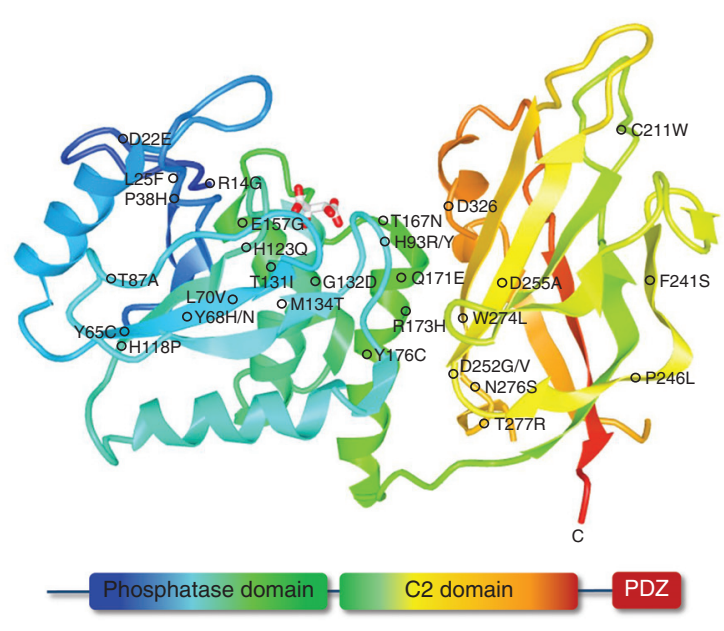

B

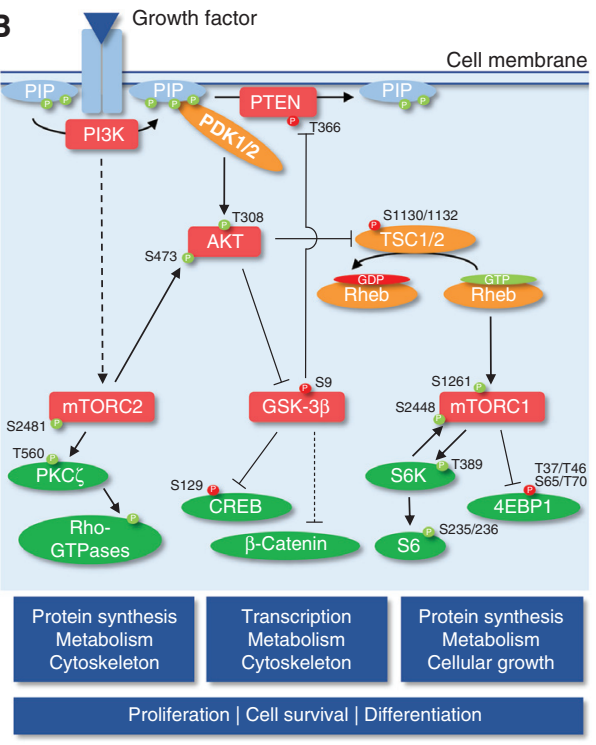

Figure 1. Phosphatase and tensin homolog (PTEN) structure and canonical phosphatidylinositol 3-phosphate kinase (PI3K)/PTEN signaling cascade. (A) Schematic representation of PTEN protein domains, together with the localization of germline missense mutations associated with ASD, developmental delay, and mental retardation (for a review, see Spinelli et al. 2015). Additional missense mutations not shown in the scheme: M1I, K6I/ E. (B) Canonical PI3K/PTEN signaling cascade. Activating phosphorylation is depicted in green, and inhibitory phosphorylation is depicted in red. Dashed lines denote multiple steps.

liferation, differentiation, and cell death (Fig. 1B). Apart from its canonical lipid phosphatase function, PTEN is important for other cellular processes using its protein phosphatase activity in a compartment-specific fashion (Hopkins et al. 2014; Kreis et al. 2014). ASD-related PTEN mutations function mostly in a dominant-negative manner resulting in an unstable but catalytically active gene product, but can also lead to altered subcellular localization. For example, whereas most of the PHTS-linked PTEN mutations are loss-of-function mutations in line with loss of PTEN's canonical tumor-suppressive role, other ASD-associated mutations lead to impaired nucleocytoplasmic shuttling (Rodríguez-Escudero et al. 2011; Tilot et al. 2014; Spinelli et al. 2015; Fricano-Kugler et al. 2018; Mingo et al. 2018).

To uncover the involvement of PTEN loss during early neuronal development of ASD, researchers have generated several promoter-driven cre/lox animal models allowing conditional Pten knockout (KO) in a spatiotemporal manner. These animals mimic several phenotypes observed in PTEN-ASD patients ranging from severe neuroanatomical alterations to the development of autistic behavior. Most importantly, these phenotypes strongly correlate with the time point of PTEN depletion. Although homozygous deletion is embryonically lethal (Di Cristofano et al. 1998), KO prior to neuronal differentiation (Pten ${ }^{f / f}$;Gfap-cre mice) results in hypertrophy, aberrant lamination of hippocampus and cerebellum, as well as seizures starting between 4 and 8 weeks and early death (Backman et al. 2001; Kwon et al.2001). Deletion shortly after neuronal differentiation $\left(\right.$ Pten $^{f f f} ;$ Nse-cre $)$ leads to delayed hypertrophy, increased arborization, and spine density together with seizures obvious after 8 months, although first autistic behavior is already present after 6 weeks (Kwon et al. 2006). Deletion in fully mature neurons (Pten ${ }^{f / f}$; CamKII $\alpha$-cre), however, does not lead to morphological changes of the hippocampus, but induces severe defects in neuronal transmission (Sperow et al. 2012). In contrast, focal adenoassociated virus (AAV)-mediated Pten $\mathrm{KO}$ in the motor cortex leads to neuronal hypertrophy, laminar disruption, and increased neuronal 
PTEN in Autism and Neurodevelopmental Disorders

arborization after 12-18 months without, however, the emergence of severe motor defects or seizures (Gutilla et al. 2016; Gallent and Steward 2018). These data show that PTEN is not only important during whole organismal development and tumor suppression, but also during neurogenesis and neuronal maintenance.

But what are the molecular mechanisms leading to these phenotypes? During embryonal and early postnatal neurodevelopment, neuronal stem cells (NSCs) and neuronal precursor cells (NPCs) proliferate, migrate to their correct position, and finally differentiate into specialized neurons or glia cells in a timely defined manner. Differentiation additionally includes neurite outgrowth, dendritic arborization, and the formation of synapses to establish neuronal circuits, which, in turn, control motor function, memory formation, speech, anxiety, or social interactions (Fig. 2; de Graaf-Peters and Hadders-Algra 2006; Reemst et al. 2016; Thion and Garel 2017). In the following sections, we will review the most important anatomical, cellular, and molecular findings from animal studies that increased the understanding into the pathogenesis of PTEN-ASD.

\section{Proliferation and Differentiation}

Early brain overgrowth and lamination defects are a commonality in multiple patients suffering from ASD. One may speculate that this pheno- type is caused by hyperproliferation of NSCs and NPCs and/or neuronal hypertrophy. Indeed, numerous studies indicate that PTENdepleted premature NSC/NPCs show shorter cell-cycle duration concomitant with higher proliferation rates, less stress response with less (naturally occurring) apoptosis, accelerated growth, migration defects, aberrant outgrowth of axons and dendrites, and altered connectivity (Gao et al. 2000; Backman et al. 2001; Groszer et al. 2001, 2006; Chenn and Walsh 2002; Li et al. 2002; Jo et al. 2012; Chen et al. 2015; Lyu et al. 2015). In the absence of PTEN, NPCs are able to differentiate both into neurons as well as into glia cells, but show a higher tendency to differentiate into neurons with enhanced neuritogenesis (Groszer et al. 2001; Jo et al. 2012; Chen et al. 2015; Lyu et al. 2015). In contrast, at postnatal stages, Pten-deficient NPCs preferentially differentiate into glia cells rather than into neurons (Chen et al. 2015). Interestingly, these outcomes seem to be restricted to NSCs but not to mesenchymal stem cells in which PTEN depletion leads to senescence rather than hyperproliferation (Duan et al. 2015).

In NSCs, PTEN predominantly localizes to the nucleus (Duan et al. 2015), which is in line with PTEN-regulating $G_{0}-G_{1}$ cell-cycle entry, genomic integrity, and preventing NSCs/NPCs from excessive self-renewal, and reaching the premature cell division limit (Ginn-Pease and Eng 2003; Groszer et al. 2006; Jo et al. 2012;

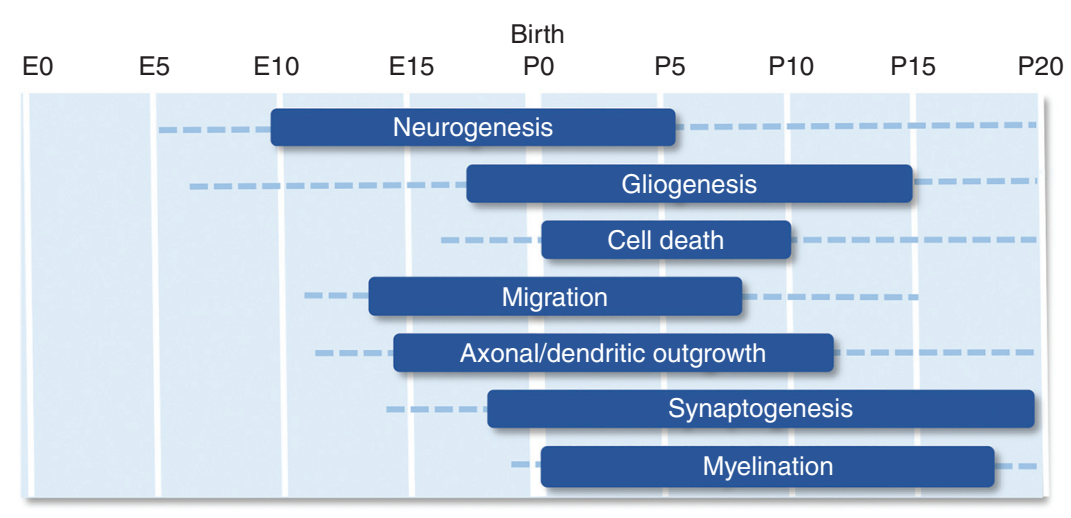

Figure 2. Stages of murine neurodevelopment. Boxes indicate peaks in the processes, dashed lines indicate that the process is active to a distinct extent. (Figures created from data in Reemst et al. 2016 and Thion and Garel 2017.) 
Feng et al. 2015; Liu et al. 2017). In postmitotic neurons, such as retinal ganglion cells, PTEN's cytosolic role is important to antagonize PI3K signaling as enriched PI3K signaling facilitates cell-cycle exit and differentiation (Jo et al. 2012). Importantly, as well as Ras/ERK signaling, the $\mathrm{PI} 3 \mathrm{~K} / \mathrm{PTEN} / \mathrm{AKT}$ axis is one central node in the fate of NSCs/NPCs, for example in the control of proliferation, differentiation, size regulation, arborization, or survival. This involvement is required in the tight and spatiotemporal integration of different signaling cues or cross talking to other signaling pathways such as Wnt/ $\beta$-catenin, Notch, brain-derived neurotrophic factor (BDNF), fibroblast growth factor 2 (FGF2), insulin-like growth factor (IGF), or epidermal growth factor (EGF) signaling.

The control of the precise transition of NSC/ NPC proliferation and differentiation involves two important pathways, the $\beta$-catenin and Notch axes, both of which regulate cAMP response element-binding protein (CREB)-mediated transcription parallel or downstream of $\mathrm{PI} 3 \mathrm{~K} / \mathrm{AKT}$, respectively. $\beta$-Catenin promotes symmetric division of radial glia $(\mathrm{RG})$ in early development, but promotes differentiation later during neurogenesis (Wrobel et al. 2007). The cross talk between PI3K and $\beta$-catenin signaling is important in this decision as AKT directly phosphorylates $\beta$-catenin and inhibits GSK$3 \beta$-induced $\beta$-catenin destruction (Polakis 2000; Fang et al. 2007). Thus, PI3K/AKT signaling leads to nuclear $\beta$-catenin accumulation and transcriptional activation via coactivators, including CREB-binding protein (CBP) or p300 (Fig. 3A). Here, either CBP or p300 may decide whether to divide or to differentiate by distinctly regulating survivin, $c-m y c$, and/or cyclinD1 expression (Ma et al. 2005; Teo et al. 2005). Additionally, $\beta$-catenin promotes RG differentiation by up-regulating $n-m y c$ and inhibiting Notch signaling (Kuwahara et al. 2010; Zinin et al. 2014). The Notch axis is another important regulator of NPC fate, which depends on PTEN activity. Upon activation, Notch intracellular domain (NICD) forms a complex with Mastermind (MAM) and recombining binding protein suppressor of hairless (RBPJ) to recruit CBP/ $\mathrm{CREB}$ and to induce expression of the transcrip- tional repressor Hes1. HES1, in turn, down-regulates proneural genes and prevents neuronal differentiation in an oscillatory manner (Shimojo et al. 2008), but also inhibits PTEN (Jo et al. 2012). Thus, AKT activity temporally increases and prevents NICD:MAM:RBPJ complex formation to terminate the Notch signaling cascade and Hes 1 expression. At a later stage, PTEN activity again increases to down-regulate AKT signaling and maintain NSCs in a proliferative state (Fig. 3B; Palomero et al. 2007; Jo et al. 2012).

Similar to cancer syndromes, in which the PTEN dosage influences tumor progression (Trotman et al. 2003), relative PTEN protein abundance has also been observed as an important regulatory characteristic in the nervous system of Pten mouse models. For instance, heterozygous Pten mutant mice show elevated $\mathrm{AKT} / \beta$-catenin signaling that coincides with macrocephaly because of excessive neuron numbers. In homozygous Pten mutant mice, however, increased $\mathrm{AKT} /$ mechanistic target of rapamycin (mTOR) signaling regulates cell size (Chen et al. 2015). These results are in line with studies showing that $\beta$-catenin overexpressing mice develop macrocephaly (Chenn and Walsh 2002), whereas $\beta$-catenin mutations result in microcephaly, ataxia, and intellectual disabilities (Dubruc et al. 2014). In contrast, PTEN depletion and accelerated AKT activity in the retina leads to decreased NICD translocation, altered CREB-mediated transcription, and premature loss of RPCs (Jo et al. 2012). Together, these results show that CREB is a central hub in neuronal development (for a review, see Sakamoto et al. 2011) and dysregulation may result in aberrant NSC/NPC proliferation and differentiation. Of importance, mutations in other CREBrelated genes lead to various syndromic autism (e.g., $\mathrm{MeCP} 2$ or $C R E B B P / E P 300)$, which are themselves causative for Rett syndrome and $\mathrm{Ru}$ binstein-Taybi syndrome, respectively (Spena et al. 2015; Lyu et al. 2016; Negri et al. 2016; Bu et al. 2017). However, additional mechanisms may be involved in the cross talk of $\beta$-catenin/ Notch/CREB axis as PTEN directly dephosphorylates CREB independently of PI3K/AKT and PTEN loss leads to up-regulation of several 
PTEN in Autism and Neurodevelopmental Disorders

A

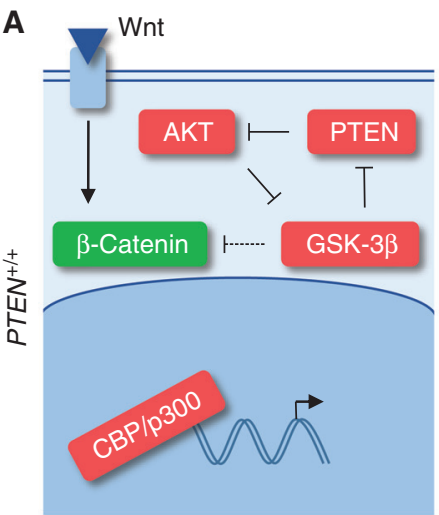

Proliferative genes $\uparrow \downarrow$

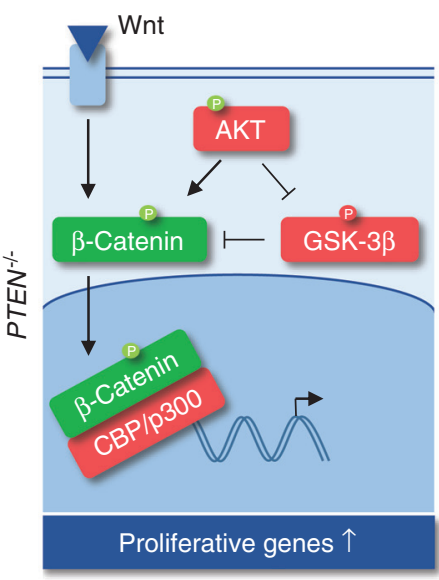

B
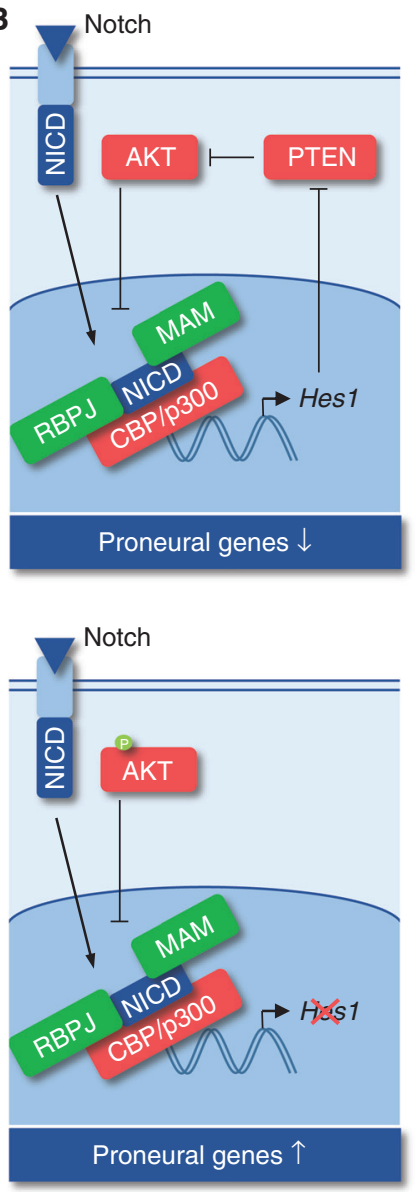

C
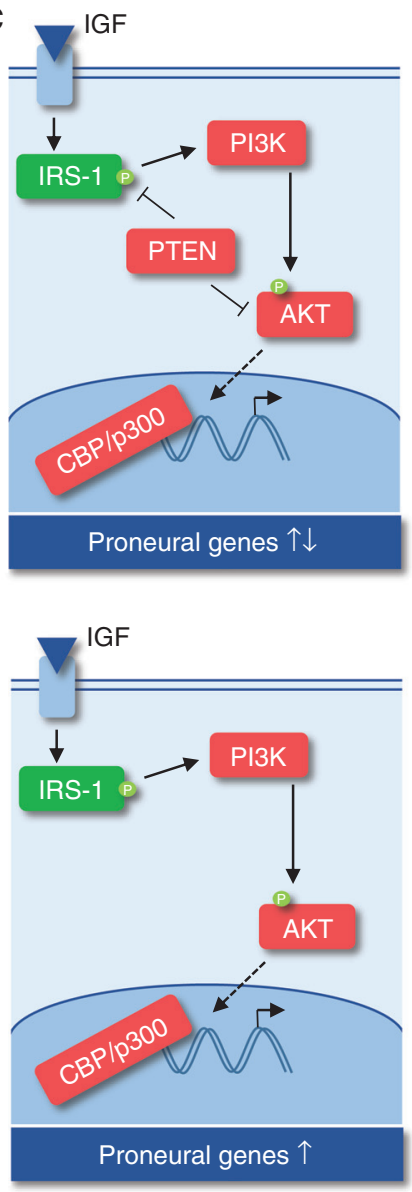

Figure 3. Cross talk between phosphatidylinositol 3-phosphate kinase (PI3K)/AKT/phosphatase and tensin homolog (PTEN) cascade with other signaling axes during proliferation and differentiation. $(A)$ Cross talk with Wnt/ $\beta$-catenin signaling. (B) Cross talk with Notch signaling. $(C)$ Cross talk with insulin-like growth factor (IGF) signaling.

CREB downstream targets, including the survival-promoting transcripts $c-m y c$ and $B c l-2$ (Gu et al. 2011) or Pax7 (Duan et al. 2015). Thus, further experiments deciphering the timely and specific role of CREB targets in Pten KO mice are needed to fully understand the precise function of PTEN in controlling proliferation and differentiation.

\section{Migration and Lamination}

During cortical development, excitatory neurons are generated from three types of NPCs: (1) RG in the ventricular zone with long ascend- ing fibers and short apical processes, which can self-renew by asymmetric division to generate one neuron and one RG; (2) apical interprogenitor cells in the ventricular zone undergoing symmetric division to generate two neurons; and (3) intermediate progenitor cells in the subventricular zone with symmetric division that form two neurons (for a review, see Paridaen and Huttner 2014; Hirota and Nakajima 2017). Several mouse models, in which Pten was conditionally deleted under the Gfap promoter, develop lamination defects especially in the cortex and hippocampus, but also in the amygdala and cerebellum (Fig. 4). These lami- 


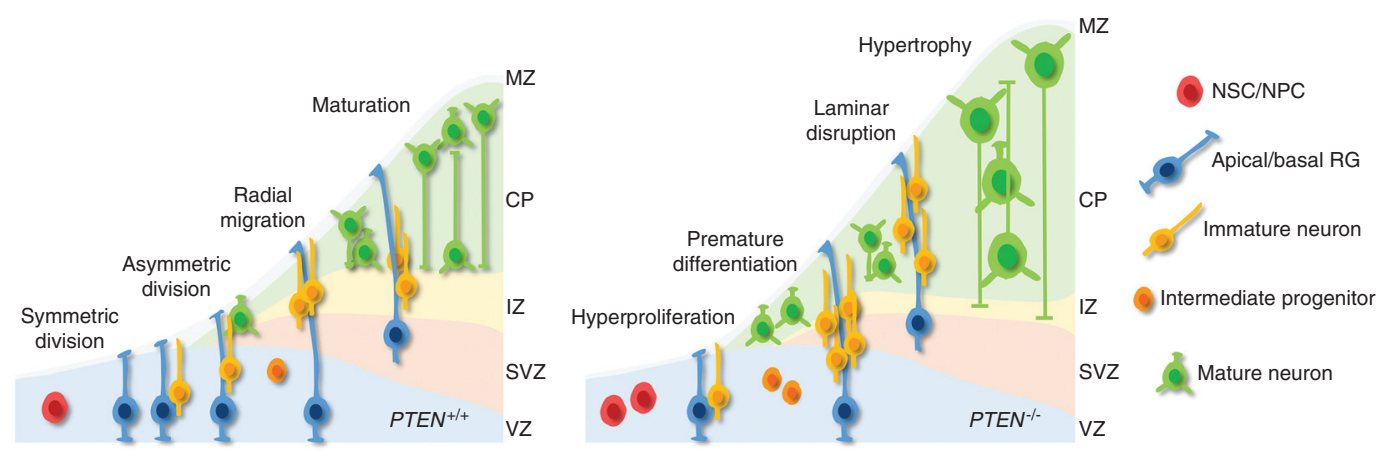

Figure 4. Cortical development in phosphatase and tensin homolog (PTEN)-positive and -negative brains. NSC, Neuronal stem cell; NPC, neuronal precursor cell; RG, radial glia; MZ, marginal zone; CP, cortical plate; IZ, intermediate zone; SVS, subventricular zone; VZ, ventricular zone.

nation defects are commonly associated with seizures and ataxia (Backman et al. 2001; Kwon et al. 2001; Wen et al. 2013). Deletion of Pten in Bergmann glia results in premature differentiation of granule cells concomitant with aberrant cerebellar lamination (Yue et al. 2005). Additionally, a reduction of Müller glia with increase of other neuronal cells is observed upon Pten deletion in the retina (Jo et al. 2012). In another study, the migration of NSCs from the subventricular zone to the olfactory bulb was analyzed in heterozygous Pten mice (Li et al. 2002). In these mice, NPCs show a more rapid radial migration into the olfactory bulb. However, consistent with other studies, this increased migration behavior does not lead to bulb overgrowth (Chen et al. 2015). Although studies commonly show lamination defects upon Pten deletion, it is not clear whether such defects result from aberrant migration or from premature differentiation (Yue et al. 2005). As stated in the section Proliferation and Differentiation, NPCs from Pten KO models show a higher tendency to differentiate into neurons rather than glia. An important regulator of asymmetric division of RGs is Notch, which exhibits an asymmetrical distribution of its intracellular signaling molecules during cell division. Here, Notch signaling maintains one daughter in a proliferative RG state, whereas the cell receiving less Notch signaling differentiates into an intermediate progenitor or neuron (Bultje et al. 2009; Dong et al. 2012). Given that Pten KO neurons exhibit aberrant Notch signaling, this could be one possible explanation for increased neurogenesis, premature loss of RGs, and lamination defects. However, further studies are needed to investigate the cell-autonomous and non-cell-autonomous effects of PTEN functions in RGs.

\section{Hypertrophy}

One of the dominant phenotypes in ASD patients with PTEN germline mutations is the development of macrocephaly. Thus, NSC/NPC hyperproliferation, together with aberrant migration, may only play a minor role in brain overgrowth. There is evidence that PTEN lossinduced neuronal hypertrophy of soma, axon, and dendrites may be responsible for this phenotype. For instance, cerebellar overgrowth in Pten $^{f f}$; Gfap-cre animals is caused by postmitotic granule cells with no indication of hyperproliferation (Kwon et al. 2001). Similarly, Pten ${ }^{f f f} ; \mathrm{Nse}$ cre Pten KO mice reveal hypertrophic mossy fibers, broader innervation of the CA3 area and misplaced cells, together with ectopic positioning of synapses (Kwon et al. 2006). This hypertrophic phenotype is a cell-autonomous effect as a result of accelerated AKT/mTOR/ S6K signaling and increased messenger RNA (mRNA) translation, rather than a response to the cellular microenvironment (Backman et al. 2001; Kwon et al. 2001, 2003; Arafa et al. 2019). In support of this, injection of the mTOR inhib- 
PTEN in Autism and Neurodevelopmental Disorders

itor CCI-779 prevents neuronal hypertrophy in Pten $^{f / f}$; Gfap-cre mice and also reduces premature death and seizure frequency (Kwon et al. 2003). In addition, nuclear PTEN has a significant impact on the regulation of soma size, although the studies are contradictory. This may be because of the differences in the models used (i.e., expression of nuclear-excluded PTEN patient mutations) (Fricano-Kugler et al. 2018), CRISPR/Cas-based introduction of the K13R mutation to prevent nuclear shuttling (Igarashi et al. 2018), or the use of the Pten ${ }^{m 3 m 4}$ mouse model showing a drop of total and nuclear PTEN (Tilot et al. 2014). Seemingly, the amount of residual PTEN load, the time point of induced PTEN-loss, and the area of modulation may have a pivotal role in the severity and specificity of phenotypes.

\section{Neurite Outgrowth and Arborization and Spine Formation}

PTEN is involved in neuronal polarization, axonal and dendritic outgrowth, and arborization, but each of these processes underlies different downstream mechanisms. Experiments using an RNAi approach show that PTEN depletion by more than $50 \%$ in hippocampal neurons results in the formation of multiple axons at the cost of dendrite formation by regulating GSK-3 $\beta$ activity (Jiang et al. 2005). This is in line with the in vivo findings from $\mathrm{Pten}^{\mathrm{f} / f}$;Nse-cre mice, which develop longer axons but also elongated and thickened dendrites in the dentate gyrus (Kwon et al. 2006). In contrast, PTEN overexpression prevents polarization of hippocampal neurons (Shi et al. 2003). These studies suggest that the PTEN/GSK-3 $\beta$ axis may be pivotal in polarization as well as axodendritic outgrowth and identity and that Pten-deficient neurons lack proper termination of axonal and dendritic growth.

Once an axon has formed, it starts to extend toward its target area. Axonal pathfinding is selectively regulated by the cellular microenvironment. Chemorepulsive or chemoattractive cues are secreted by surrounding cells that bind to specific receptors on axonal growth cones (e.g., semaphorin/plexin, draxin/DCC, or neurotro- phins) (for a review, see Russell and Bashaw 2018). A common downstream event of these repulsive ligand-receptor interactions is the reorganization of the actin/microtubule cytoskeleton and $\beta$-integrin removal to induce growth cone collapse and prevent outgrowth (Henle et al. 2013). There is growing evidence that chemorepulsion depends on PTEN by downregulating $\mathrm{PIP}_{3}$ levels and antagonizing AKT signaling, whereas chemoattraction is PTEN independent (Henle et al. 2013). PTEN distributes in the growth cone and translocates to the membrane upon repulsive stimulation with Sema3A, which results in decreases in $\mathrm{PIP}_{3} / \mathrm{AKT}$ signaling and activation of GSK-3 $\beta$ (Chadborn et al. 2006). It has been shown that GSK-3 $\beta$ is, at least in part, crucial to induce Sema3A-mediated growth cone collapse by the modulation of F-actin dynamics (Fig. 5A; Eickholt et al. 2002). Apart from F-actin remodeling during chemorepulsion, the PTEN/GSK-3 $\beta$ axis organizes microtubule dynamics in a number of different ways. First, PTEN regulates microtubule detyrosination and PTEN depletion results in hyperstabilization of microtubules together with increased axonal outgrowth in hippocampal neurons (Kath et al. 2018). Second, GSK-3 $\beta$ phosphorylates several microtubule-associated proteins (e.g., MOB1, Tau, MAP1B) to regulate microtubule assembly and to prevent neurite outgrowth (Wagner et al. 1996; Meli et al. 2015; Song et al. 2018). For instance, the chemorepellent draxin uses GSK-3 $\beta$ to phosphorylate MAP1B and to prevent axonal growth concomitant with Draxin KO in mice leading to severe morphological changes of different brain structures including the corpus callosum (Ahmed et al. 2011; Meli et al. 2015). There are numerous examples clearly indicating that PI3K/PTEN signaling is essential for accurate guidance of axons; it is furthermore relevant for mediating cellular adhesion to the extracellular matrix as PTEN depletion results in less removal of focal adhesions in zebrafish spinal cord (Henle et al. 2013).

Cytoskeletal remodeling further requires local translation of proteins to regulate neuritogenesis and arborization. Mechanistically, a well-regulated interplay between the mTORC1 
S. Rademacher and B.J. Eickholt
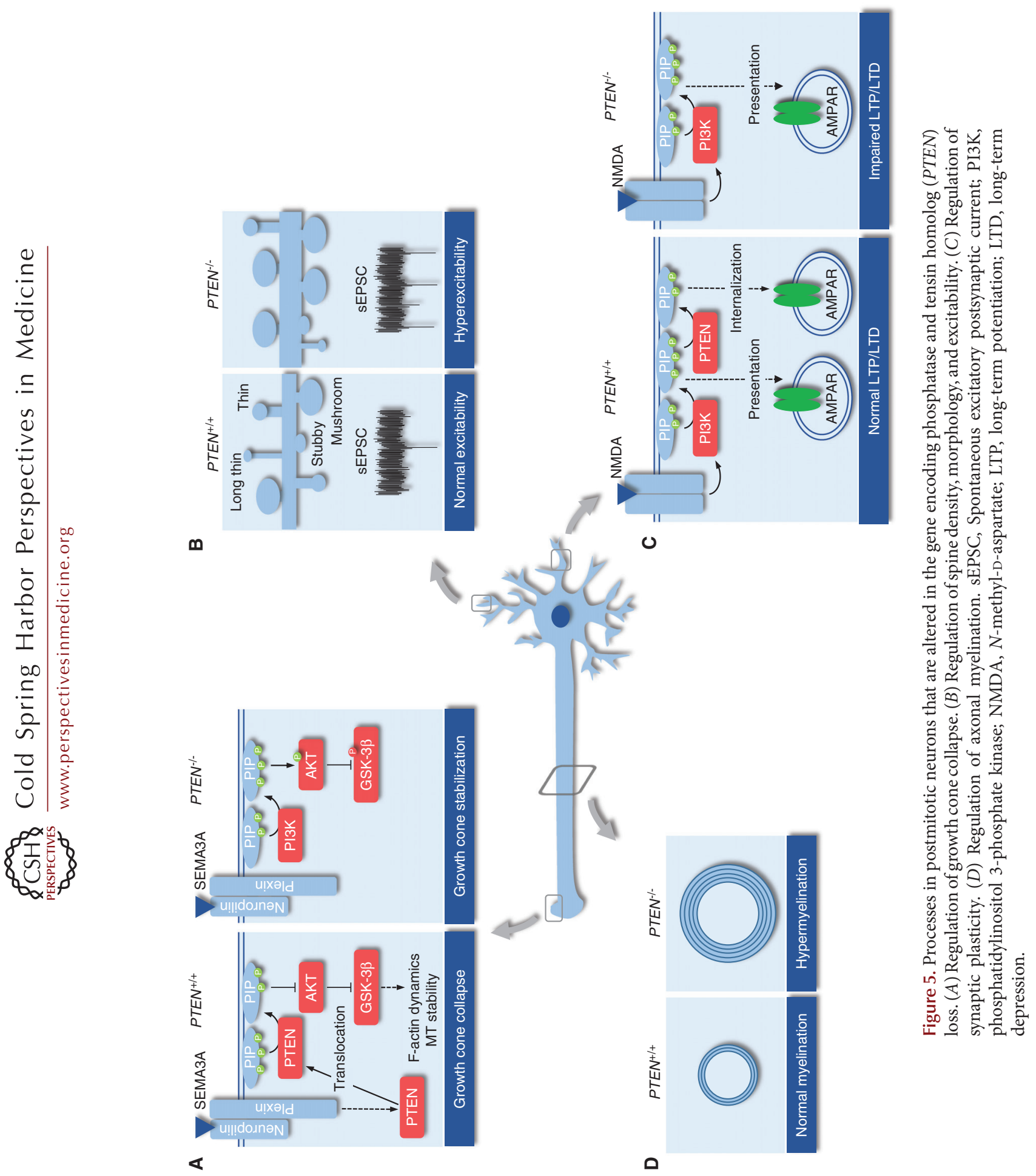
PTEN in Autism and Neurodevelopmental Disorders

and mTORC2 complexes drives these processes in hippocampal neurons (Urbanska et al. 2012), distinctly by mTORC1 promoting mRNA translation via $\mathrm{p} 70 \mathrm{~S} 6 \mathrm{~K}$ or by $\mathrm{mTORC} 2$ regulating actin dynamics via RhoGTPases (Jacinto et al. 2004; Sarbassov et al. 2004; Jaworski et al. 2005). To allow for increased local mTOR activity and dendrite growth or branching to occur, local PTEN depletion is essential. Indeed, it has been shown that NEDD-4, an E3-ligase that catalyses PTEN ubiquitination and proteasomal degradation (Wang et al. 2007), is a regulator of axonal branching (Drinjakovic et al. 2010; Christie et al. 2012; Hsia et al. 2014).

NEDD-4 furthermore regulates PTEN nuclear translocation by monoubiquitination (Trotman et al. 2007; Wang et al. 2007). PTEN's nuclear role during axonogenesis is not completely understood, but it has been shown that PTEN interacts with the APC-CDH1 complex (Song et al. 2011) and that this complex drives the expression of different cues important for axonal growth (Lasorella et al. 2006). PTEN localization has been systematically analyzed in the developing brain during neurito- and synaptogenesis. Interestingly, during neuritogenesis, PTEN is mainly localized in the nucleus and sparsely found in dendrites, but retranslocates into mature dendrites to antagonize mTOR signaling, pause arborization, and promote synaptogenesis (Perandones et al. 2004). These data overlap with the narrow time window, in which mTOR inhibitors are able to reverse aberrant outgrowth defects in a tuberous sclerosis complex $\left(T s c 1^{f / f} ; G f p\right.$-cre) model of autism (Cox et al. 2018). Thus, a spatial regulation of PTEN localization is important for proper neuritogenesis, and constant PTEN (nuclear) depletion leads to increased axodendritogenesis with increased synaptogenesis possibly caused by hyperactive mTOR signaling. Given that Pten loss leads to diminished growth cone collapse, increased axonal and dendritic outgrowth, and more focal adhesions, it is plausible that Pten-deficient neurons cannot stop growing in a timely fashion and form ectopic synapses. Consequently, this effect will have a significant impact on neuronal connectivity, synaptic plasticity, and the development of autistic behavior.

\section{PTEN in Connectivity and LTP/LTD}

PTEN-ASD patients as well as Pten cKO mice develop behavioral abnormalities, including aberrant social interactions, problems in communication, impaired cognition and memory, repetitive behavior, and altered fear/anxiety (Kwon et al. 2006; Sperow et al. 2012; Lugo et al. 2014; Smith et al. 2016; Hodges et al. 2018). Pten cKO animals have been analyzed for synaptic connectivity and plasticity, showing that there is an imbalance between synaptic excitation and inhibition (E/I balance), which is now well accepted as a key pathological mechanism linked to developing ASD-related behavior (Lee et al. 2017). Systematic approaches involve studies in which Cre-expressing virus or shRNA against Pten has been injected into the dentate gyrus (Luikart et al. 2011; Williams et al. 2015; Skelton et al. 2019), amygdala (Haws et al. 2014), or auditory cortex (Xiong et al. 2012) of neonatal mice. Although differences in spine density upon Pten deletion have been observed, which may be because of different time points of virus injection and tissue specificity (P7 dentate gyrus vs. P49 basolateral amygdala vs. Pten ${ }^{f / f} ;$ Nse-cre), the number of mature mushroom-like spines is increased compared to controls (Haws et al. 2014; Williams et al. 2015). Additionally, Pten $\mathrm{KO}$ neurons receive accelerated afferent input from multiple neurons (Skelton et al. 2019). As a consequence, neurons require a higher firing threshold to evoke an action potential but, at the same time, are more sensitive to afferent stimulation and fire more readily as shown by higher excitatory postsynaptic current (EPSC) frequency and amplitude (Fig. 5B; Luikart et al. 2011; Haws et al. 2014; Williams et al. 2015; Skelton et al. 2019). Inhibitory input on these neurons is unchanged (Williams et al.2015), indicating that Pten deletion in excitatory neurons makes them hyperexcitable. On the other hand, compelling studies show an involvement of GABAergic inhibitory interneurons. Pten ${ }^{f / f} ; N k \times 2.1$-cre mice with Pten deletion in the medial ganglionic eminence demonstrate a preferential loss of somatostatin- over parvalbumin-positive GABAergic interneurons, but, at the same time, show a twofold increase of induced pluripotent stem cells 
(iPSCs) on layer II/III excitatory neurons concomitant with autistic behavior (Vogt et al. 2015). In this study, we have also analyzed the effect of ASD-related PTEN mutations in a knockin model and observed similar effects on the ratio of somatostatin/parvalbumin-positive interneurons (Vogt et al. 2015). Together, these results indicate that changes in afferent input render neurons either hyper- or hypoexcitable, potentially providing the strongest causal link to the development of ASD-related behavior. Such a mechanistic relationship has also been observed in other ASD models including Rett syndrome (Wood et al. 2009).

PTEN-ASD subjects and mice often develop (or are prone to) seizures, a condition of synchronized pathological firing, and it is accepted that neuronal hyperexcitability is a driving force for epileptogenesis. Aberrant circuitry of the dentate gyrus because of ectopic migration, hypertrophy, and hyperexcitability has been shown to result in increased spontaneous EPSCs, fewer iPSCs, and multiple population spikes and is also a wellknown factor for temporal lobe epilepsy (Nadler 2003; Pun et al. 2012; LaSarge et al. 2016; Santos et al. 2017). From a molecular point of view, an involvement of potassium channels in hippocampal hyperexcitability of 8 -week-old Pten ${ }^{\text {flf; }}$; Gfap-cre mice has been implicated (Lugo et al. 2014; Nguyen and Anderson 2018). Another interesting point is that induction of status epilepticus in Pten ${ }^{f / f}$; Gfap-cre mice, in which granule cells are mainly affected by Pten deletion, results in more severe hyperactivity and impairment in social behavior compared to animals that have not undergone seizures (Smith et al. 2016).

Along with E/I imbalance and development of seizures, Pten deletion alters synaptic plasticity in an age- and brain region-dependent manner. For instance, Pten cKO (Pten ${ }^{f / f} ; \mathrm{Nse}$-cre $)$ enhances theta burst-induced long-term potentiation (LTP) in dentate granule neurons of young (8-12 weeks) animals, but completely impairs LTP in older (20-30 week) animals (Takeuchi et al. 2013). Comparably, Pten cKO decreases LTP at CA3-CA1 synapses of 8-weekold Pten ${ }^{f / f}$;CamKII $\alpha$-cre mice (Sperow et al. 2012) or Pten ${ }^{f / f}$;Gfap-cre mice (Fig. 5C; Fraser et al. 2008). Additionally, $N$-methyl-D-aspartate
(NMDA) receptor (NMDAR)- and metabotropic glutamate receptor (mGluR)-dependent long-term depression (LTD) are impaired in these mice at all time points analyzed (Sperow et al. 2012; Takeuchi et al. 2013), whereas acute pharmacological inhibition of PTEN lipid phosphatase activity prevents only NMDAR-dependent LTD but not mGluR-dependent LTD nor LTP (Jurado et al. 2010). These data suggest that PTEN depletion early during development leads to aberrant synaptic strength and connectivity along with morphological changes, whereas mature neurons respond with altered synaptic plasticity. Anatomical and morphological correlates, together with the frequency and severity of seizures upon early or late PTEN modulation, further strengthen this hypothesis. Importantly, the first signs of ASD-related behavior and seizures occur prior to severe morphological changes in Pten ${ }^{f / f}$;Nse-cre mice (Kwon et al. 2006; Takeuchi et al. 2013).

But how does this happen? On the one hand, long-term Pten deletion may lead to further synaptic/cellular defects that remain to be determined. On the other hand, it may be the case that aberrant plasticity induced by Pten loss may involve additional PI3K-dependent as well as PI3K-independent actions of the phosphatase. For example, the F-actin-stabilizing protein drebrin is an important regulator of spine formation, maintenance, synaptic plasticity, context-dependent fear learning, and social behavior (Hayashi and Shirao 1999; Kojima et al. 2010; Koganezawa et al. 2017). In young adults, drebrin loss does not result in any discernible phenotypes nor alter synaptic plasticity under physiological conditions (Willmes et al. 2017), whereas its overexpression leads to abnormal filopodia formation in immature neurons, spine elongation in mature neurons, and E/I imbalance (Hayashi and Shirao 1999; Mizui et al. 2005; Ivanov et al. 2009). Moreover, gabazine treatment, which induces seizure-like network activity, results in drebrin hyperphosphorylation (Kreis et al. 2013), potentially involving hyperactivity-induced local production of reactive oxygen species (ROS) and activation of the ATM kinase to protect spines during aging (Kreis et al. 2019). Because PTEN dephosphor- 
PTEN in Autism and Neurodevelopmental Disorders

ylates drebrin independently of PI3K signaling leading to drebrin destabilization (Kreis et al. 2013; Kreis et al. 2019), it could be assumed that Pten loss does not counteract the increased drebrin phosphorylation during seizures. It may be the case that Pten deletion further promotes spine enlargement and synaptic strengthening by using the actin-stabilizing activity of drebrin. Such a PI3K-independent effect of PTEN could be one explanation of why co-KO of $P d k 1$ $\left(\right.$ Pten $^{f / f} ; P d k 1^{f / f} ;$ CamKII $\alpha$-cre $)$, a positive regulator of mTOR, rescues LTP and LTD deficits, but is ineffective in rescuing impairments in spatial memory formation in Pten ${ }^{\text {flf }}$; CamKII $\alpha$-cre mice (Sperow et al. 2012). In addition to drebrin, PTEN interacts with PSD-95 via its PDZ-binding domain and is recruited to the PSD upon NMDA stimulation in a biphasic fashion to regulate $\mathrm{PIP}_{3}$ signaling during LTP and LTD (Jurado et al. 2010; Arendt et al. 2014). Interestingly, the protein levels of PSD-95 as well as other postsynaptic proteins, including mGluR5 or Kv4.2, are down-regulated in Pten ${ }^{\text {flf }}$;Gfap-cre animals, whereas other ASD-related scaffolding proteins, including FMRP, Shank, or Sapap1, are up-regulated (Lugo et al. 2014), further suggesting molecular commonalities between neurodevelopmental disorders.

\section{PTEN and Myelination}

During neuritogenesis, oligodendrocytes and Schwann cells myelinate the newly formed axon in the central nervous system (CNS) or peripheral nervous system (PNS), respectively. Tremendous thickening of myelin sheaths with aberrant myelin compaction, abnormal formation of nodes of Ranvier, and reduced g-ratio (i.e., the ratio of the inner axonal diameter to the total axonal diameter) have been observed in Pten ${ }^{f / f}$;Gfap-Cre (Fraser et al. 2008), Pten ${ }^{f / f}$; Olig2-cre (Harrington et al. 2010; Maire et al. 2014), Pten f/f; Cnp1-cre (Goebbels et al. 2010), or Pten ${ }^{f / f}$;Pdgfra-cre (González-Fernández et al. 2018) mouse models, especially in the corpus callosum and spinal cord (Fig. 5D). In contrast, reduced myelin sheath thickness with increased g-ratio in the corpus callosum caused by the inability of oligodendrocytes to properly target and ensheath axons has been described in homozygous Pten ${ }^{m 3 m 4}$ mice (Lee et al. 2019). Although different models have been used to analyze axonal myelination, the mice collectively show increased cerebral white matter, which is a common phenotype in patients harboring PTEN mutations (Vanderver et al. 2014; Frazier et al. 2015). Additionally, these studies report on aberrant oligodendrocyte precursor cell proliferation, migration, and differentiation (Maire et al. 2014; González-Fernández et al. 2018; Lee et al. 2019), increased myelin synthesis (Harrington et al. 2010; González-Fernández et al. 2018; Lee et al. 2019), defective myelin storage (Lee et al. 2019), and decreased myelin compaction (Fraser et al. 2008; Lee et al. 2019). As such, the inability of Pten ${ }^{m 3 m 4}$ oligodendrocytes to correctly wrap axons has been proposed to be caused by aberrant maturation and precocious myelin spreading making the myelin sheath dysfunctional (Lee et al. 2019).

Mechanistically, CNS myelination has been linked to mTOR signaling, as myelination defects in Pten ${ }^{\mathrm{f} / f}$;Cpn1-cre mice can be rescued by the application of rapamycin (Goebbels et al. 2010). However, mTOR double cKO (Pten ${ }^{\text {flf; }}$; Mtor ${ }^{f / f}$;Pdgfra-cre) does not ameliorate the phenotypes seen in Pten $^{f / f} ;$ Pdgfra-cre animals, which has led to the hypothesis that PTEN's effect on myelin synthesis involves GSK-3 $\beta$ (González-Fernández et al. 2018). Based on this model, constant PTEN depletion in mature oligodendrocytes results in decreased GSK-3 $\beta$ and increased mTORC1 activity to facilitate myelination. However, increased GSK- $3 \beta$ phosphorylation is not observed in oligodendrocytes from mice expressing hyperactive AKT (Narayanan et al. 2009). A similar model has been proposed for Schwann cells, in which high mTORC1 activity suppresses Schwann cell differentiation, whereas physiological activity promotes myelin synthesis and axon wrapping (Figlia et al. 2017). As well as the cell-autonomous effects upon altered mTOR and GSK-3 $\beta$ activities, other signaling pathways or regulatory factors may influence myelination. For instance, transient PTEN inhibition potentiates IGF-1mediated oligodendrocyte precursor differentiation and myelination in collaboration of PI3K/ 
AKT and MEK/ERK pathways (De Paula et al. 2014). Similarly, Wnt/ $\beta$-catenin signaling is absolutely essential for normal axonal myelination (for a review, see Gaesser and Fyffe-Maricich 2016), which has not yet been studied in Pten cKO oligodendrocytes. PTEN interacts also with several scaffolding and polarization proteins, including Dlg1 or Par3, and interferes with $\beta$ integrin signaling. In Schwann cells, Dlg1 has been identified as a negative regulator of axon ensheathing by up-regulating PTEN (Cotter et al. 2010). However, in oligodendrocytes, myelination of CNS axons appears to be independent on Dlg1 (Brinkmann et al. 2008), indicating that further molecules may be important. Interestingly, it has been shown that $\beta 1$ integrin is important during myelination by up-regulating AKT activity (Barros et al. 2009). Given that $\beta 1$ integrin removal upon chemorepulsive stimulation is PTEN dependent in neuronal growth cones (Henle et al. 2013), one could speculate that PTEN depletion in oligodendrocytes has a similar effect on $\beta 1$ integrin removal. Axon caliber is another determinant during myelination in the CNS and recent evidence comes from one study showing that secreted factors from Pten ${ }^{f / f}$ Nex-cre granule cell axons regulate their myelination by wild-type oligodendrocytes (Goebbels et al. 2017).

In conclusion, there has been significant progress in understanding the function of PTEN during myelination. It will be relevant to analyze whether Pten-deficiency-induced myelination phenotypes impact on the progression of developmental disorders and epilepsy. For example, it will be interesting to analyze in detail whether the PTEN-depletion-induced myelination defect in the corpus callosum contributes to epilepsy and behavioral deficits, especially as corpus callosotomy is considered as a surgical procedure for some children suffering from interhemispheric seizures (Luat et al. 2017).

\section{CONCLUDING REMARKS}

cKO mouse models have emerged as valuable tools to understand specific spatiotemporal roles of PTEN during development and its impact on human developmental disorders including ASD. Using these models, significant progress has been made in determining cell-autonomous and cell-intrinsic effects that result as a consequence of Pten deletion. However, cKO models do not reflect entirely the patients' situation, because the latter harbor heterozygous PTEN germline mutations but do not possess specific PTEN null neurons. The timing of the neurodevelopmental processes described in this review (proliferation, migration, differentiation, neuronal connection, synaptic plasticity, and axonal myelination) is intermingled and the understanding of how the actual pathomechanism of PTEN-ASD relies on a dysregulation of a specific event is unclear. Comprehensive analysis of the cellular, anatomical, electrophysiological, and behavioral observations of models, in which ASD-related mutations have been introduced in the Pten allele(s), will be valuable. More physiological models, which have been adopted to date in only a few studies (Vogt et al. 2015; Lee et al. 2019), will have the advantage of showing mutant Pten expression in all tissues, cells, and progenitors at the same time. Similarly, PTEN PI3K-independent but also phosphatase-independent processes need to be considered further to comprehend the multifaceted contributions of PTEN to neuronal development and function. Correlating these results with the data obtained from cKO models could be a valuable step in understanding ASD development and to optimize the time window of treatment strategies.

\section{ACKNOWLEDGMENTS}

We thank Joachim Fuchs (Institute of Biochemistry, Charité - Universitätsmedizin Berlin) for critically reviewing this manuscript.

\section{REFERENCES}

Ahmed G, Shinmyo Y, Ohta K, Islam SM, Hossain M, Naser IB, Riyadh MA, Su Y, Zhang S, Tessier-Lavigne M, et al. 2011. Draxin inhibits axonal outgrowth through the netrin receptor DCC. J Neurosci 31: 14018-14023. doi:10 .1523 /jneurosci.0943-11.2011

Arafa SR, LaSarge CL, Pun RYK, Khademi S, Danzer SC. 2019. Self-reinforcing effects of mTOR hyperactive neu- 
PTEN in Autism and Neurodevelopmental Disorders

rons on dendritic growth. Exp Neurol 311: 125-134 doi:10.1016/j.expneurol.2018.09.019

Arendt KL, Benoist M, Lario A, Draffin JE, Munoz M, Esteban JA. 2014. PTEN counteracts PIP3 upregulation in spines during NMDA-receptor-dependent long-term depression. J Cell Sci 127: 5253-5260. doi:10.1242/jcs .156554

Backman SA, Stambolic V, Suzuki A, Haight J, Elia A, Pretorius J, Tsao MS, Shannon P, Bolon B, Ivy GO, et al. 2001. Deletion of Pten in mouse brain causes seizures, ataxia and defects in soma size resembling Lhermitte-Duclos disease. Nat Genet 29: 396-403. doi:10.1038/ng782

Barros CS, Nguyen T, Spencer KS, Nishiyama A, Colognato H, Muller U. 2009. $\beta 1$ Integrins are required for normal CNS myelination and promote AKT-dependent myelin outgrowth. Development 136: 2717-2724. doi:10.1242/ dev.038679

Brinkmann BG, Agarwal A, Sereda MW, Garratt AN, Muller T, Wende H, Stassart RM, Nawaz S, Humml C, Velanac V, et al. 2008. Neuregulin-1/ErbB signaling serves distinct functions in myelination of the peripheral and central nervous system. Neuron 59: 581-595. doi:10.1016/j .neuron.2008.06.028

Bu Q, Wang A, Hamzah H, Waldman A, Jiang K, Dong Q, Li R, Kim J, Turner D, Chang Q. 2017. CREB signaling is involved in Rett syndrome pathogenesis. J Neurosci 37: 3671-3685. doi:10.1523/jneurosci.3735-16.2017

Bultje RS, Castaneda-Castellanos DR, Jan LY, Jan YN, Kriegstein AR, Shi SH. 2009. Mammalian Par3 regulates progenitor cell asymmetric division via notch signaling in the developing neocortex. Neuron 63: 189-202. doi:10.1016/j .neuron.2009.07.004

Butler MG, Dasouki MJ, Zhou XP, Talebizadeh Z, Brown M, Takahashi TN, Miles JH, Wang CH, Stratton R, Pilarski R, et al. 2005. Subset of individuals with autism spectrum disorders and extreme macrocephaly associated with germline PTEN tumour suppressor gene mutations. $J$ Med Genet 42: 318-321. doi:10.1136/jmg.2004.024646

Chadborn NH, Ahmed AI, Holt MR, Prinjha R, Dunn GA, Jones GE, Eickholt BJ. 2006. PTEN couples Sema3A signaling to growth cone collapse. J Cell Sci 119: 951-957. doi: $10.1242 /$ jcs. 02801

Chen Y, Huang WC, Sejourne J, Clipperton-Allen AE, Page DT. 2015. Pten mutations alter brain growth trajectory and allocation of cell types through elevated $\beta$-catenin signaling. J Neurosci 35: 10252-10267. doi:10.1523/jneur osci.5272-14.2015

Chenn A, Walsh CA. 2002. Regulation of cerebral cortical size by control of cell cycle exit in neural precursors. Science 297: 365-369. doi:10.1126/science. 1074192

Christie KJ, Martinez JA, Zochodne DW. 2012. Disruption of E3 ligase NEDD4 in peripheral neurons interrupts axon outgrowth: Linkage to PTEN. Mol Cell Neurosci 50: 179-192. doi:10.1016/j.mcn.2012.04.006

Cotter L, Ozcelik M, Jacob C, Pereira JA, Locher V, Baumann R, Relvas JB, Suter U, Tricaud N. 2010. Dlg1-PTEN interaction regulates myelin thickness to prevent damaging peripheral nerve overmyelination. Science 328: 14151418. doi:10.1126/science. 1187735

Courchesne E, Carper R, Akshoomoff N. 2003. Evidence of brain overgrowth in the first year of life in autism. JAMA 290: 337-344. doi:10.1001/jama.290.3.337
Courchesne E, Pierce K, Schumann CM, Redcay E, Buckwalter JA, Kennedy DP, Morgan J. 2007. Mapping early brain development in autism. Neuron 56: 399-413. doi:10 $.1016 /$ j.neuron.2007.10.016

Cox RL, Calderon de Anda F, Mangoubi T, Yoshii A. 2018. Multiple critical periods for rapamycin treatment to correct structural defects in Tsc-1-suppressed brain. Front Mol Neurosci 11: 409. doi:10.3389/fnmol.2018.00409

de Graaf-Peters VB, Hadders-Algra M. 2006. Ontogeny of the human central nervous system: What is happening when? Early Hum Dev 82: 257-266. doi:10.1016/j .earlhumdev.2005.10.013

De Paula ML, Cui QL, Hossain S, Antel J, Almazan G. 2014. The PTEN inhibitor bisperoxovanadium enhances myelination by amplifying IGF-1 signaling in rat and human oligodendrocyte progenitors. Glia 62: 64-77. doi:10 $.1002 /$ glia.22584

Di Cristofano A, Pesce B, Cordon-Cardo C, Pandolfi PP. 1998. Pten is essential for embryonic development and tumor suppression. Nat Genet 19: 348-355. doi:10.1038/ 1235

Dong Z, Yang N, Yeo SY, Chitnis A, Guo S. 2012. Intralineage directional Notch signaling regulates self-renewal and differentiation of asymmetrically dividing radial glia. Neuron 74: 65-78. doi:10.1016/j.neuron.2012.01.031

Donovan AP, Basson MA. 2017. The neuroanatomy of autism-A developmental perspective. J Anat 230: 4-15. doi:10.1111/joa.12542

Drinjakovic J, Jung H, Campbell DS, Strochlic L, Dwivedy A, Holt CE. 2010. E3 ligase Nedd4 promotes axon branching by downregulating PTEN. Neuron 65: 341-357. doi:10 $.1016 /$ j.neuron.2010.01.017

Duan S, Yuan G, Liu X, Ren R, Li J, Zhang W, Wu J, Xu X, Fu L, Li Y, et al. 2015. PTEN deficiency reprogrammes human neural stem cells towards a glioblastoma stem celllike phenotype. Nat Commun 6: 10068. doi:10.1038/ ncomms 10068

Dubruc E, Putoux A, Labalme A, Rougeot C, Sanlaville D, Edery P. 2014. A new intellectual disability syndrome caused by CTNNB1 haploinsufficiency. Am J Med Genet A 164: 1571-1575. doi:10.1002/ajmg.a.36484

Eickholt BJ, Walsh FS, Doherty P. 2002. An inactive pool of GSK-3 at the leading edge of growth cones is implicated in Semaphorin 3A signaling. J Cell Biol 157: 211-217. doi:10 $.1083 /$ jcb. 200201098

Fang D, Hawke D, Zheng Y, Xia Y, Meisenhelder J, Nika H, Mills GB, Kobayashi R, Hunter T, Lu Z. 2007. Phosphorylation of $\beta$-catenin by AKT promotes $\beta$-catenin transcriptional activity. J Biol Chem 282: 11221-11229. doi:10.1074/jbc.M611871200

Feng J, Liang J, Li J, Li Y, Liang H, Zhao X, McNutt MA, Yin Y. 2015. PTEN controls the DNA replication process through MCM2 in response to replicative stress. Cell Rep 13: 1295-1303. doi:10.1016/j.celrep.2015.10.016

Figlia G, Norrmén C, Pereira JA, Gerber D, Suter U. 2017. Dual function of the PI3K-Akt-mTORC1 axis in myelination of the peripheral nervous system. eLife 6: e29241. doi:10.7554/eLife.29241

Fraser MM, Bayazitov IT, Zakharenko SS, Baker SJ. 2008. Phosphatase and tensin homolog, deleted on chromosome 10 deficiency in brain causes defects in synaptic structure, transmission and plasticity, and myelination 
abnormalities. Neuroscience 151: 476-488. doi:10.1016/j .neuroscience.2007.10.048

Frazier TW, Embacher R, Tilot AK, Koenig K, Mester J, Eng C. 2015. Molecular and phenotypic abnormalities in individuals with germline heterozygous PTEN mutations and autism. Mol Psychiatry 20: 1132-1138. doi:10.1038/ mp.2014.125

Fricano-Kugler CJ, Getz SA, Williams MR, Zurawel AA, DeSpenza T Jr, Frazel PW, Li M, O’Malley AJ, Moen EL, Luikart BW. 2018. Nuclear excluded autism-associated phosphatase and tensin homolog mutations dysregulate neuronal growth. Biol Psychiatry 84: 265-277. doi:10 .1016/j.biopsych.2017.11.025

Gaesser JM, Fyffe-Maricich SL. 2016. Intracellular signaling pathway regulation of myelination and remyelination in the CNS. Exp Neurol 283: 501-511. doi:10.1016/j expneurol.2016.03.008

Gallent EA, Steward O. 2018. Neuronal PTEN deletion in adult cortical neurons triggers progressive growth of cell bodies, dendrites, and axons. Exp Neurol 303: 12-28. doi:10.1016/j.expneurol.2018.01.005

Gao X, Neufeld TP, Pan D. 2000. Drosophila PTEN regulates cell growth and proliferation through PI3K-dependent and -independent pathways. Dev Biol 221: 404-418. doi:10.1006/dbio.2000.9680

Ginn-Pease ME, Eng C. 2003. Increased nuclear phosphatase and tensin homologue deleted on chromosome 10 is associated with $\mathrm{G}_{0}-\mathrm{G}_{1}$ in MCF-7 cells. Cancer Res 63: 282-286.

Goebbels S, Oltrogge JH, Kemper R, Heilmann I, Bormuth I, Wolfer S, Wichert SP, Mobius W, Liu X, Lappe-Siefke C, et al. 2010. Elevated phosphatidylinositol 3,4,5-trisphosphate in glia triggers cell-autonomous membrane wrapping and myelination. J Neurosci 30: 8953-8964. doi:10 .1523/jneurosci.0219-10.2010

Goebbels S, Wieser GL, Pieper A, Spitzer S, Weege B, Yan K, Edgar JM, Yagensky O, Wichert SP, Agarwal A, et al. 2017. A neuronal $\mathrm{PI}(3,4,5) \mathrm{P}_{3}$-dependent program of oligodendrocyte precursor recruitment and myelination. Nat Neurosci 20: 10-15. doi:10.1038/nn.4425

Goffin A, Hoefsloot LH, Bosgoed E, Swillen A, Fryns JP. 2001. PTEN mutation in a family with Cowden syndrome and autism. Am J Med Genet 105: 521-524. doi:10.1002/ ajmg.1477

González-Fernández E, Jeong HK, Fukaya M, Kim H, Khawaja RR, Srivastava IN, Waisman A, Son YJ, Kang SH. 2018. PTEN negatively regulates the cell lineage progression from $\mathrm{NG}^{+}$glial progenitor to oligodendrocyte via mTOR-independent signaling. eLife 7: e32021. doi:10 .7554/eLife.32021

Groszer M, Erickson R, Scripture-Adams DD, Lesche R, Trumpp A, Zack JA, Kornblum HI, Liu X, Wu H. 2001. Negative regulation of neural stem/progenitor cell proliferation by the Pten tumor suppressor gene in vivo. Science 294: 2186-2189. doi:10.1126/science.1065518

Groszer M, Erickson R, Scripture-Adams DD, Dougherty JD, Le Belle J, Zack JA, Geschwind DH, Liu X, Kornblum $\mathrm{HI}, \mathrm{Wu} \mathrm{H}$. 2006. PTEN negatively regulates neural stem cell self-renewal by modulating $\mathrm{G}_{0}-\mathrm{G}_{1}$ cell cycle entry. Proc Natl Acad Sci 103: 111-116. doi:10.1073/pnas .0509939103
Gu T, Zhang Z, Wang J, Guo J, Shen WH, Yin Y. 2011. CREB is a novel nuclear target of PTEN phosphatase. Cancer Res 71: 2821-2825. doi:10.1158/0008-5472.CAN-10-3399

Gutilla EA, Buyukozturk MM, Steward O. 2016. Long-term consequences of conditional genetic deletion of PTEN in the sensorimotor cortex of neonatal mice. Exp Neurol 279: 27-39. doi:10.1016/j.expneurol.2016.02.013

Harrington EP, Zhao C, Fancy SP, Kaing S, Franklin RJ, Rowitch DH. 2010. Oligodendrocyte PTEN is required for myelin and axonal integrity, not remyelination. Ann Neurol 68: 703-716. doi:10.1002/ana.22090

Haws ME, Jaramillo TC, Espinosa F, Widman AJ, Stuber GD, Sparta DR, Tye KM, Russo SJ, Parada LF, Stavarache $\mathrm{M}$, et al. 2014. PTEN knockdown alters dendritic spine/ protrusion morphology, not density. J Comp Neurol 522: 1171-1190. doi:10.1002/cne.23488

Hayashi K, Shirao T. 1999. Change in the shape of dendritic spines caused by overexpression of drebrin in cultured cortical neurons. J Neurosci 19: 3918-3925. doi:10.1523/ jneurosci.19-10-03918.1999

Henle SJ, Carlstrom LP, Cheever TR, Henley JR. 2013. Differential role of PTEN phosphatase in chemotactic growth cone guidance. J Biol Chem 288: 20837-20842. doi:10.1074/jbc.C113.487066

Hirota Y, Nakajima K. 2017. Control of neuronal migration and aggregation by reelin signaling in the developing cerebral cortex. Front Cell Dev Biol 5: 40. doi:10.3389/fcell .2017 .00040

Hodges SL, Reynolds CD, Smith GD, Jefferson TS, Gao N, Morrison JB, White J, Nolan SO, Lugo JN. 2018. Neuronal subset-specific deletion of Pten results in aberrant Wnt signaling and memory impairments. Brain Res 1699: 100-106. doi:10.1016/j.brainres.2018.08.007

Hopkins BD, Hodakoski C, Barrows D, Mense SM, Parsons RE. 2014. PTEN function: The long and the short of it. Trends Biochem Sci 39: 183-190. doi:10.1016/j.tibs.2014 .02 .006

Hsia HE, Kumar R, Luca R, Takeda M, Courchet J, Nakashima J, Wu S, Goebbels S, An W, Eickholt BJ, et al. 2014. Ubiquitin E3 ligase Nedd4-1 acts as a downstream target of PI3K/PTEN-mTORC1 signaling to promote neurite growth. Proc Natl Acad Sci 111: 13205-13210. doi:10 .1073/pnas.1400737111

Igarashi A, Itoh K, Yamada T, Adachi Y, Kato T, Murata D, Sesaki H, Iijima M. 2018. Nuclear PTEN deficiency causes microcephaly with decreased neuronal soma size and increased seizure susceptibility. J Biol Chem 293: $9292-$ 9300. doi:10.1074/jbc.RA118.002356

Ivanov A, Esclapez M, Pellegrino C, Shirao T, Ferhat L. 2009. Drebrin A regulates dendritic spine plasticity and synaptic function in mature cultured hippocampal neurons. $J$ Cell Sci 122: 524-534. doi:10.1242/jcs.033464

Jacinto E, Loewith R, Schmidt A, Lin S, Rüegg MA, Hall A, Hall MN. 2004. Mammalian TOR complex 2 controls the actin cytoskeleton and is rapamycin insensitive. Nat Cell Biol 6: 1122-1128. doi:10.1038/ncb1183

Jaworski J, Spangler S, Seeburg DP, Hoogenraad CC, Sheng M. 2005. Control of dendritic arborization by the phosphoinositide- $3^{\prime}$-kinase-Akt-mammalian target of rapamycin pathway. J Neurosci 25: 11300-11312. doi:10 .1523/jneurosci.2270-05.2005 
Jiang H, Guo W, Liang X, Rao Y. 2005. Both the establishment and the maintenance of neuronal polarity require active mechanisms: critical roles of GSK-3 $\beta$ and its upstream regulators. Cell 120: 123-135. doi:10.1016/j.cell .2004 .12 .033

Jo HS, Kang KH, Joe CO, Kim JW. 2012. Pten coordinates retinal neurogenesis by regulating Notch signaling. EMBO J 31: 817-828. doi:10.1038/emboj.2011.443

Jurado S, Benoist M, Lario A, Knafo S, Petrok CN, Esteban JA. 2010. PTEN is recruited to the postsynaptic terminal for NMDA receptor-dependent long-term depression. EMBO J 29: 2827-2840. doi:10.1038/emboj.2010.160

Kath C, Goni-Oliver P, Müller R, Schultz C, Haucke V, Eickholt B, Schmoranzer J. 2018. PTEN suppresses axon outgrowth by down-regulating the level of detyrosinated microtubules. PLoS ONE 13: e0193257. doi:10 .1371/journal.pone.0193257

Kennedy DP, Courchesne E. 2008. The intrinsic functional organization of the brain is altered in autism. Neuroimage 39: 1877-1885. doi:10.1016/j.neuroimage.2007.10.052

Koganezawa N, Hanamura K, Sekino Y, Shirao T. 2017. The role of drebrin in dendritic spines. Mol Cell Neurosci 84: 85-92. doi:10.1016/j.mcn.2017.01.004

Kojima N, Hanamura K, Yamazaki H, Ikeda T, Itohara S, Shirao T. 2010. Genetic disruption of the alternative splicing of drebrin gene impairs context-dependent fear learning in adulthood. Neuroscience 165: 138-150. doi:10 .1016/j.neuroscience.2009.10.016

Kreis P, Hendricusdottir R, Kay L, Papageorgiou IE, van Diepen M, Mack T, Ryves J, Harwood A, Leslie NR, Kann O, et al. 2013. Phosphorylation of the actin binding protein Drebrin at $S 647$ is regulated by neuronal activity and PTEN. PLoS ONE 8: e71957. doi:10.1371/journal .pone.0071957

Kreis P, Leondaritis G, Lieberam I, Eickholt BJ. 2014. Subcellular targeting and dynamic regulation of PTEN: Implications for neuronal cells and neurological disorders. Front Mol Neurosci 7: 23. doi:10.3389/fnmol.2014.00023

Kreis P, Gallrein C, Rojas-Puente E, Mack TGA, Kroon C, Dinkel V, Willmes C, Murk K, Tom-Dieck S, Schuman EM, et al. 2019. ATM phosphorylation of the actin-binding protein drebrin controls oxidation stress-resistance in mammalian neurons and C. elegans. Nat Commun 10: 486. doi:10.1038/s41467-019-08420-w

Kuwahara A, Hirabayashi Y, Knoepfler PS, Taketo MM, Sakai J, Kodama T, Gotoh Y. 2010. Wnt signaling and its downstream target $\mathrm{N}$-myc regulate basal progenitors in the developing neocortex. Development 137: 1035-1044. doi:10.1242/dev.046417

Kwon CH, Zhu X, Zhang J, Knoop LL, Tharp R, Smeyne RJ, Eberhart CG, Burger PC, Baker SJ. 2001. Pten regulates neuronal soma size: A mouse model of Lhermitte-Duclos disease. Nat Genet 29: 404-411. doi:10.1038/ng781

Kwon CH, Zhu X, Zhang J, Baker SJ. 2003. mTor is required for hypertrophy of Pten-deficient neuronal soma in vivo. Proc Natl Acad Sci 100: 12923-12928. doi:10.1073/pnas .2132711100

Kwon CH, Luikart BW, Powell CM, Zhou J, Matheny SA, Zhang W, Li Y, Baker SJ, Parada LF. 2006. Pten regulates neuronal arborization and social interaction in mice. Neuron 50: 377-388. doi:10.1016/j.neuron.2006.03.023
LaSarge CL, Pun RY, Muntifering MB, Danzer SC. 2016. Disrupted hippocampal network physiology following PTEN deletion from newborn dentate granule cells. Neurobiol Dis 96: 105-114. doi:10.1016/j.nbd.2016.09.004

Lasorella A, Stegmüller J, Guardavaccaro D, Liu G, Carro MS, Rothschild G, de la Torre-Ubieta L, Pagano M, Bonni A, Iavarone A. 2006. Degradation of Id 2 by the anaphasepromoting complex couples cell cycle exit and axonal growth. Nature 442: 471-474. doi:10.1038/nature04895

Lee E, Lee J, Kim E. 2017. Excitation/inhibition imbalance in animal models of autism spectrum disorders. Biol Psychiatry 81: 838-847. doi:10.1016/j.biopsych.2016.05.011

Lee H, Thacker S, Sarn N, Dutta R, Eng C. 2019. Constitutional mislocalization of Pten drives precocious maturation in oligodendrocytes and aberrant myelination in model of autism spectrum disorder. Transl Psychiatry 9: 13. doi:10.1038/s41398-018-0364-7

Leslie NR, Longy M. 2016. Inherited PTEN mutations and the prediction of phenotype. Semin Cell Dev Biol 52: 3038. doi:10.1016/j.semcdb.2016.01.030

Li L, Liu F, Salmonsen RA, Turner TK, Litofsky NS, Di Cristofano A, Pandolfi PP, Jones SN, Recht LD, Ross AH. 2002. PTEN in neural precursor cells: Regulation of migration, apoptosis, and proliferation. Mol Cell Neurosci 20: 21-29. doi:10.1006/mcne.2002.1115

Liu Y, Du X, Zhang S, Liu Y, Zhang Q, Yin Q, McNutt MA, Yin Y. 2017. PTEN regulates spindle assembly checkpoint timing through MAD1 in interphase. Oncotarget 8: 98040-98050. doi:10.18632/oncotarget.20532

Luat AF, Asano E, Kumar A, Chugani HT, Sood S. 2017. Corpus callosotomy for intractable epilepsy revisited: The children's hospital of michigan series. J Child Neurol 32: 624-629. doi:10.1177/0883073817697847

Lugo JN, Smith GD, Arbuckle EP, White J, Holley AJ, Floruta CM, Ahmed N, Gomez MC, Okonkwo O. 2014. Deletion of PTEN produces autism-like behavioral deficits and alterations in synaptic proteins. Front Mol Neurosci 7: 27. doi:10.3389/fnmol.2014.00027

Luikart BW, Schnell E, Washburn EK, Bensen AL, Tovar KR, Westbrook GL. 2011. Pten knockdown in vivo increases excitatory drive onto dentate granule cells. J Neurosci 31: 4345-4354. doi:10.1523/jneurosci.0061-11.2011

Lyu J, Yu X, He L, Cheng T, Zhou J, Cheng C, Chen Z, Cheng G, Qiu Z, Zhou W. 2015. The protein phosphatase activity of PTEN is essential for regulating neural stem cell differentiation. Mol Brain 8: 26. doi:10.1186/s13041015-0114-1

Lyu JW, Yuan B, Cheng TL, Qiu ZL, Zhou WH. 2016. Reciprocal regulation of autism-related genes $\mathrm{MeCP} 2$ and PTEN via microRNAs. Sci Rep 6: 20392. doi:10.1038/ srep20392

Ma H, Nguyen C, Lee KS, Kahn M. 2005. Differential roles for the coactivators $\mathrm{CBP}$ and $\mathrm{p} 300$ on $\mathrm{TCF} / \beta$-cateninmediated survivin gene expression. Oncogene 24: 36193631. doi:10.1038/sj.onc. 1208433

Maire CL, Ramkissoon S, Hayashi M, Haidar S, Ramkissoon L, DiTomaso E, Ligon KL. 2014. Pten loss in Olig2 expressing neural progenitor cells and oligodendrocytes leads to interneuron dysplasia and leukodystrophy. Stem Cells 32: 313-326. doi:10.1002/stem.1590

Meli R, Weisova P, Propst F. 2015. Repulsive axon guidance by draxin is mediated by protein kinase B (Akt), glycogen 


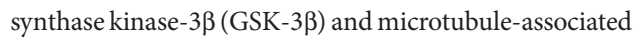
protein 1B. PLoS ONE 10: e0119524. doi:10.1371/journal .pone.0119524

Mingo J, Rodríguez-Escudero I, Luna S, Fernández-Acero T, Amo L, Jonasson AR, Zori RT, López JI, Molina M, Cid VJ, et al. 2018. A pathogenic role for germline PTEN variants which accumulate into the nucleus. Eur J Hum Genet 26: 1180-1187. doi:10.1038/s41431-018-0155-x

Mizui T, Takahashi H, Sekino Y, Shirao T. 2005. Overexpression of drebrin $\mathrm{A}$ in immature neurons induces the accumulation of F-actin and PSD-95 into dendritic filopodia, and the formation of large abnormal protrusions. Mol Cell Neurosci 30: 149-157. doi:10.1016/j.mcn.2005 .06 .008

Nadler JV. 2003. The recurrent mossy fiber pathway of the epileptic brain. Neurochem Res 28: 1649-1658. doi:10 .1023/A:1026004904199

Narayanan SP, Flores AI, Wang F, Macklin WB. 2009. Akt signals through the mammalian target of rapamycin pathway to regulate CNS myelination. J Neurosci 29: 6860-6870. doi:10.1523/jneurosci.0232-09.2009

Negri G, Magini P, Milani D, Colapietro P, Rusconi D, Scarano E, Bonati MT, Priolo M, Crippa M, Mazzanti L, et al 2016. From whole gene deletion to point mutations of EP300-positive Rubinstein-Taybi patients: New insights into the mutational spectrum and peculiar clinical hallmarks. Hum Mutat 37: 175-183. doi:10.1002/humu .22922

Nguyen LH, Anderson AE. 2018. mTOR-dependent alterations of Kv1.1 subunit expression in the neuronal subsetspecific Pten knockout mouse model of cortical dysplasia with epilepsy. Sci Rep 8: 3568. doi:10.1038/s41598-01821656-8

Palomero T, Sulis ML, Cortina M, Real PJ, Barnes K, Ciofani M, Caparros E, Buteau J, Brown K, Perkins SL, et al. 2007. Mutational loss of PTEN induces resistance to NOTCH1 inhibition in T-cell leukemia. Nat Med 13: 1203-1210. doi:10.1038/nm1636

Paridaen JT, Huttner WB. 2014. Neurogenesis during development of the vertebrate central nervous system. $E M B O$ Rep 15: 351-364. doi:10.1002/embr.201438447

Perandones C, Costanzo RV, Kowaljow V, Pivetta OH, Carminatti H, Radrizzani M. 2004. Correlation between synaptogenesis and the PTEN phosphatase expression in dendrites during postnatal brain development. Brain Res Mol Brain Res 128: 8-19. doi:10.1016/j.molbrainres .2004 .05 .021

Polakis P. 2000. Wnt signaling and cancer. Genes Dev 14: 1837-1851. doi:10.1101/gad.14.15.1837

Pun RY, Rolle IJ, Lasarge CL, Hosford BE, Rosen JM, Uhl JD, Schmeltzer SN, Faulkner C, Bronson SL, Murphy BL, et al. 2012. Excessive activation of mTOR in postnatally generated granule cells is sufficient to cause epilepsy. Neuron 75: 1022-1034. doi:10.1016/j.neuron.2012.08.002

Ramaswami G, Geschwind DH. 2018. Genetics of autism spectrum disorder. Handb Clin Neurol 147: 321-329. doi:10.1016/B978-0-444-63233-3.00021-X

Reemst K, Noctor SC, Lucassen PJ, Hol EM. 2016. The indispensable roles of microglia and astrocytes during brain development. Front Hum Neurosci 10: 566. doi:10.3389/ fnhum.2016.00566
Rodríguez-Escudero I, Oliver MD, Andrés-Pons A, Molina M, Cid VJ, Pulido R. 2011. A comprehensive functional analysis of PTEN mutations: Implications in tumor- and autism-related syndromes. Hum Mol Genet 20: 41324142. doi:10.1093/hmg/ddr337

Russell SA, Bashaw GJ. 2018. Axon guidance pathways and the control of gene expression. Dev Dyn 247: 571-580. doi:10.1002/dvdy.24609

Sakamoto K, Karelina K, Obrietan K. 2011. CREB: A multifaceted regulator of neuronal plasticity and protection. J Neurochem 116: 1-9. doi:10.1111/j.1471-4159.2010 .07080.x

Santos VR, Pun RYK, Arafa SR, LaSarge CL, Rowley S, Khademi S, Bouley T, Holland KD, Garcia-Cairasco N, Danzer SC. 2017. PTEN deletion increases hippocampal granule cell excitability in male and female mice. Neurobiol Dis 108: 339-351. doi:10.1016/j.nbd.2017.08.014

Sarbassov DD, Ali SM, Kim DH, Guertin DA, Latek RR, Erdjument-Bromage H, Tempst P, Sabatini DM. 2004. Rictor, a novel binding partner of mTOR, defines a rapamycin-insensitive and raptor-independent pathway that regulates the cytoskeleton. Curr Biol 14: 1296-1302. doi:10.1016/j.cub.2004.06.054

Shi SH, Jan LY, Jan YN. 2003. Hippocampal neuronal polarity specified by spatially localized $\mathrm{mPar} 3 / \mathrm{mPar} 6$ and PI 3 kinase activity. Cell 112: 63-75. doi:10.1016/S0092-8674 (02)01249-7

Shimojo H, Ohtsuka T, Kageyama R. 2008. Oscillations in notch signaling regulate maintenance of neural progenitors. Neuron 58: 52-64. doi:10.1016/j.neuron.2008.02 .014

Skelton PD, Frazel PW, Lee D, Suh H, Luikart BW. 2019. Pten loss results in inappropriate excitatory connectivity. Mol Psychiatry. doi:10.1038/s41380-019-0412-6

Smith GD, White J, Lugo JN. 2016. Superimposing status epilepticus on neuron subset-specific PTEN haploinsufficient and wild type mice results in long-term changes in behavior. Sci Rep 6: 36559. doi:10.1038/srep36559

Song MS, Carracedo A, Salmena L, Song SJ, Egia A, Malumbres M, Pandolfi PP. 2011. Nuclear PTEN regulates the APC-CDH1 tumor-suppressive complex in a phosphatase-independent manner. Cell 144: 187-199. doi:10 .1016/j.cell.2010.12.020

Song Z, Han X, Zou H, Zhang B, Ding Y, Xu X, Zeng J, Liu J, Gong A. 2018. PTEN-GSK3ß-MOB1 axis controls neurite outgrowth in vitro and in vivo. Cell Mol Life Sci 75: 4445-4464. doi:10.1007/s00018-018-2890-0

Spena S, Milani D, Rusconi D, Negri G, Colapietro P, Elcioglu N, Bedeschi F, Pilotta A, Spaccini L, Ficcadenti A, et al. 2015. Insights into genotype-phenotype correlations from $C R E B B P$ point mutation screening in a cohort of 46 Rubinstein-Taybi syndrome patients. Clin Genet 88: 431-440. doi:10.1111/cge.12537

Sperow M, Berry RB, Bayazitov IT, Zhu G, Baker SJ, Zakharenko SS. 2012. Phosphatase and tensin homologue (PTEN) regulates synaptic plasticity independently of its effect on neuronal morphology and migration. J Physiol 590: 777-792. doi:10.1113/jphysiol.2011.220236

Spinelli L, Black FM, Berg JN, Eickholt BJ, Leslie NR. 2015. Functionally distinct groups of inherited PTEN mutations in autism and tumour syndromes. J Med Genet 52: 128-134. doi:10.1136/jmedgenet-2014-102803 
PTEN in Autism and Neurodevelopmental Disorders

Takeuchi K, Gertner MJ, Zhou J, Parada LF, Bennett MV, Zukin RS. 2013. Dysregulation of synaptic plasticity precedes appearance of morphological defects in a Pten conditional knockout mouse model of autism. Proc Natl Acad Sci 110: 4738-4743. doi:10.1073/pnas. 1222803110

Teo JL, Ma H, Nguyen C, Lam C, Kahn M. 2005. Specific inhibition of $\mathrm{CBP} / \beta$-catenin interaction rescues defects in neuronal differentiation caused by a presenilin-1 mutation. Proc Natl Acad Sci 102: 12171-12176. doi:10.1073/ pnas.0504600102

Thion MS, Garel S. 2017. On place and time: microglia in embryonic and perinatal brain development. Curr Opin Neurobiol 47: 121-130. doi:10.1016/j.conb.2017.10.004

Tilot AK, Gaugler MK, Yu Q, Romigh T, Yu W, Miller RH, Frazier TW II, Eng C. 2014. Germline disruption of Pten localization causes enhanced sex-dependent social motivation and increased glial production. Hum Mol Genet 23: 3212-3227. doi:10.1093/hmg/ddu031

Trotman LC, Niki M, Dotan ZA, Koutcher JA, Di Cristofano A, Xiao A, Khoo AS, Roy-Burman P, Greenberg NM, Van Dyke T, et al. 2003. Pten dose dictates cancer progression in the prostate. PLoS Biol 1: E59. doi:10.1371/journal.pbio .0000059

Trotman LC, Wang X, Alimonti A, Chen Z, Teruya-Feldstein J, Yang H, Pavletich NP, Carver BS, Cordon-Cardo C, Erdjument-Bromage H, et al. 2007. Ubiquitination regulates PTEN nuclear import and tumor suppression. Cell 128: 141-156. doi:10.1016/j.cell.2006.11.040

Urbanska M, Gozdz A, Swiech LJ, Jaworski J. 2012. Mammalian target of rapamycin complex 1 (mTORC1) and 2 (mTORC2) control the dendritic arbor morphology of hippocampal neurons. J Biol Chem 287: 30240-30256. doi:10.1074/jbc.M112.374405

Vanderver A, Tonduti D, Kahn I, Schmidt J, Medne L, Vento J, Chapman KA, Lanpher B, Pearl P, Gropman A, et al. 2014. Characteristic brain magnetic resonance imaging pattern in patients with macrocephaly and PTEN mutations. Am J Med Genet A 164: 627-633. doi:10.1002/ajmg .a.36309

Vogt D, Cho KKA, Lee AT, Sohal VS, Rubenstein JLR. 2015. The parvalbumin/somatostatin ratio is increased in Pten mutant mice and by human PTEN ASD alleles. Cell Rep 11: 944-956. doi:10.1016/j.celrep.2015.04.019

Wagner U, Utton M, Gallo JM, Miller CC. 1996. Cellular phosphorylation of tau by GSK- $3 \beta$ influences tau binding to microtubules and microtubule organisation. J Cell Sci 109: $1537-1543$.
Wang X, Trotman LC, Koppie T, Alimonti A, Chen Z, Gao Z, Wang J, Erdjument-Bromage H, Tempst P, CordonCardo C, et al. 2007. NEDD4-1 is a proto-oncogenic ubiquitin ligase for PTEN. Cell 128: 129-139. doi:10 $.1016 /$ j.cell.2006.11.039

Wen Y, Li W, Choudhury GR, He R, Yang T, Liu R, Jin K, Yang SH. 2013. Astroglial PTEN loss disrupts neuronal lamination by dysregulating radial glia-guided neuronal migration. Aging Dis 4: 113-126.

Williams MR, DeSpenza T Jr, Li M, Gulledge AT, Luikart BW. 2015. Hyperactivity of newborn Pten knock-out neurons results from increased excitatory synaptic drive. $J$ Neurosci 35: 943-959. doi:10.1523/jneurosci.3144-14 .2015

Willmes CG, Mack TG, Ledderose J, Schmitz D, Wozny C, Eickholt BJ. 2017. Investigation of hippocampal synaptic transmission and plasticity in mice deficient in the actinbinding protein Drebrin. Sci Rep 7: 42652. doi:10.1038/ srep42652

Wood L, Gray NW, Zhou Z, Greenberg ME, Shepherd GM. 2009. Synaptic circuit abnormalities of motor-frontal layer $2 / 3$ pyramidal neurons in an RNA interference model of methyl-CpG-binding protein 2 deficiency. J Neurosci 29: 12440-12448. doi:10.1523/jneurosci.3321-09.2009

Wrobel CN, Mutch CA, Swaminathan S, Taketo MM, Chenn A. 2007. Persistent expression of stabilized $\beta$-catenin delays maturation of radial glial cells into intermediate progenitors. Dev Biol 309: 285-297. doi:10.1016/j.ydbio. 2007 .07 .013

Xiong Q, Oviedo HV, Trotman LC, Zador AM. 2012. PTEN regulation of local and long-range connections in mouse auditory cortex. J Neurosci 32: 1643-1652. doi:10.1523/ jneurosci.4480-11.2012

Yue Q, Groszer M, Gil JS, Berk AJ, Messing A, Wu H, Liu X. 2005. PTEN deletion in Bergmann glia leads to premature differentiation and affects laminar organization. Development 132: 3281-3291. doi:10.1242/dev.01891

Zinin N, Adameyko I, Wilhelm M, Fritz N, Uhlen P, Ernfors P, Henriksson MA. 2014. MYC proteins promote neuronal differentiation by controlling the mode of progenitor cell division. EMBO Rep 15: 383-391. doi:10.1002/embr .201337424

Zori RT, Marsh DJ, Graham GE, Marliss EB, Eng C. 1998. Germline PTEN mutation in a family with Cowden syndrome and Bannayan-Riley-Ruvalcaba syndrome. Am J Med Genet 80: 399-402. doi:10.1002/(SICI)1096-8628 (19981204)80:4<399::AID-AJMG18>3.0.CO;2-O 


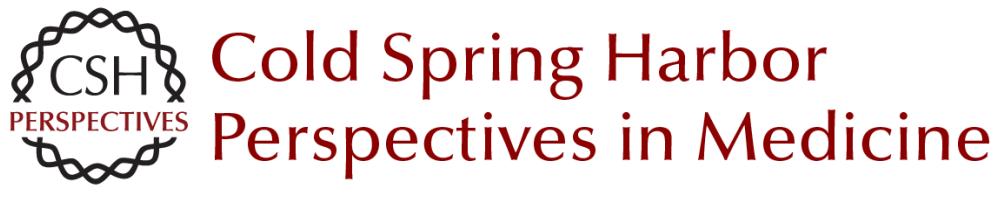

\section{PTEN in Autism and Neurodevelopmental Disorders}

Sebastian Rademacher and Britta J. Eickholt

Cold Spring Harb Perspect Med 2019; doi: 10.1101/cshperspect.a036780 originally published online August 19, 2019

\section{Subject Collection The PTEN Family}

PTEN in Regulating Hematopoiesis and Leukemogenesis

Yilin Wu, Haichuan Zhu and Hong Wu

Connecting Genotype with Behavioral Phenotype

in Mouse Models of Autism Associated with

PTEN Mutations

Amy E. Clipperton-Allen and Damon T. Page

Metabolic Role of PTEN in Insulin Signaling and

Resistance

Yu Zhe Li, Antonio Di Cristofano and Minna Woo

Posttranslational Regulation and Conformational

Plasticity of PTEN

Larissa Kotelevets, Barbara Trifault, Eric Chastre, et al.

Toward Systems Pathology for PTEN Diagnostics Nahal Haddadi, Glena Travis, Najah T. Nassif, et al.

PTEN in Hereditary and Sporadic Cancer Joanne Ngeow and Charis Eng

PTEN Mouse Models of Cancer Initiation and Progression Yu-Ru Lee and Pier Paolo Pandolfi

Dual-Specific Protein and Lipid Phosphatase

PTEN and Its Biological Functions

Taojian Tu, Jingyu Chen, Lulu Chen, et al.
PTEN: Bridging Endocytosis and Signaling Matthew F. Lee and Lloyd C. Trotman

PTEN as a Guardian of the Genome: Pathways and Targets

Xinyi Fan, Jeffrey Kraynak, Jonathan P.S. Knisely, et al.

Discovery of the PTEN Tumor Suppressor and Its Connection to the PI3K and AKT Oncogenes Ramon Parsons

The Complex Landscape of PTEN mRNA

Regulation

Erin Sellars, Martino Gabra and Leonardo Salmena

PTEN Nuclear Functions Jason Ho, Edward S. Cruise, Ryan J.O. Dowling, et al.

Structural Mechanisms of PTEN Regulation Glenn R. Masson and Roger L. Williams

PTEN in Chromatin Remodeling Jingyi Yang and Yuxin Yin

The Role of PTEN in Innate and Adaptive Immunity

Henry Taylor, Arian D. J. Laurence and Holm H. Uhlig

For additional articles in this collection, see http://perspectivesinmedicine.cshlp.org/cgi/collection/ 